\title{
Electroanalysis based on stand-alone matrices and electrode-modifying films with silica sol-gel frameworks: a review
}

\author{
Krzysztof Miecznikowski ${ }^{1}$ (D) James A. Cox ${ }^{2}$
}

Received: 29 April 2020 /Revised: 1 June 2020 / Accepted: 1 June 2020 / Published online: 1 August 2020

(C) The Author(s) 2020

\begin{abstract}
Silica sol-gel matrices and its organically modified analogues that contain aqueous electrolytes, ionic liquids, or other ionic conductors constitute stand-alone solid-state electrochemical cells when hosting electrodes or serve as modifying films on working electrodes in conventional cells. These materials facilitate a wide variety of analytical applications and are employed in various designs of power sources. In this review, analytical applications are the focus. Solid-state cells that serve as gas sensors, including in chromatographic detectors of gas-phase analytes, are described. Sol-gel films that modify working electrodes to perform functions such as hosting electrochemical catalysts and acting as size-exclusion moieties that protect the electrode from passivation by adsorption of macromolecules are discussed with emphasis on pore size, structure, and orientation. Silica sol-gel chemistry has been studied extensively; thus, factors that control its general properties as frameworks for solid-state cells and for thin films on the working electrode are well characterized. Here, recent advances such as the use of dendrimers and of nanoscale beads in conjunction with electrochemically assisted deposition of silica to template pore size and distribution are emphasized. Related topics include replacing aqueous solutions as the internal electrolyte with room-temperature ionic liquids, using the solgel as an anchor for functional groups and modifying electrodes with silica-based composites.
\end{abstract}

Keywords Amperometric gas sensors $\cdot$ Solid electrolytes $\cdot$ Nanowells $\cdot$ Three-phase boundary $\cdot$ Silica $\cdot$ Templated pores

\section{Introduction}

Applications of electrochemistry to both measurement science and power production require consideration of perturbation of the surface from sample matrix components and from products of the electrochemical process. The frequent need for a catalyst is a second general factor. Sol-gel processing comprises an approach to address these limitations. Inorganic silica sol-gels and the

Dedication: Dedicated to Professor Fritz Scholz on the occasion of his $65^{\text {th }}$ birthday

Krzysztof Miecznikowski

kmiecz@chem.uw.edu.pl

James A. Cox

coxja@miamioh.edu

1 Faculty of Chemistry, University of Warsaw, Pasteura 1, 02-093 Warsaw, Poland

2 Department of Chemistry and Biochemistry, Miami University, Oxford, OH 45056, USA related organically modified forms, namely ormosils, are materials that can address these problems. As films on the electrode surface, they can host catalysts; moreover, these films can be formulated to reject matrix components that can potentially foul the electrode. Recent studies have provided evidence that controlling pore size the films provides a degree of enhanced stability and selectivity via size-exclusion of species that can otherwise transport to the base electrode.

A second general application of electrochemically inactive sol-gels is to provide a framework for measurement of gases. Such structures host the components of an electrochemical cell, namely the working, counter, and reference electrodes and the supporting electrolyte. Because of the nature of the framework, they are commonly considered solid-state cells even though the hosted electrolyte is generally a liquid. These cells are particularly suited to the sensing of gaseous analytes either by measurement after extraction into the electrolyte or by reaction at the three-phase boundary comprising the working electrode, the gaseous sample, and the sol-gel surface. 
The sequence of adaptation of sol-gel processing to electrochemical applications is summarized in representative review articles [1-11], and the fundamentals of sol-gel processing are described by Brinker and Scherer [12]. In summary, the precursor is commonly $\mathrm{SiR}_{4}$ where $\mathrm{R}$ represents alkoxy groups, typically methoxy or ethoxy. The polymerization is initiated by either acids or bases. With acids, linear -Si-O-Sichains result; they pack closely yielding a microporous material. With bases, the significant branching occurs rather than formation of linear chains; the result in greater spacing among the -Si-O- groups, thereby yielding mesopores. The common distinction is that micropores refer to diameters below $2 \mathrm{~nm}$; mesopores, 2-50 nm; and macropores, above $50 \mathrm{~nm}$. These products contain residual water and are termed herein as solgels. Dehydration leads to the formation of xerogels. When the precursor has one or more non-oxo organic group, the product is termed an ormosil (organically modified sol-gel). Dehydration by super-critical extraction keeps the silica framework from collapsing; these low-density products are named aerogels. Increasing attention is being paid to sol-gel processing in room-temperature ionic liquids to form ionogels. This review will focus on (1) the use of these forms of silica in modification of electrode surfaces, especially matters related to control of pore size and its relation to electrochemical performance, and (2) the fabrication of frameworks that can host two- and three-electrodes and an electrolyte for the purpose of direct electrochemical determination of gasphase analytes.

\section{Electrode modification with silica sol-gel films}

A general question is what purposes can be served by a nonelectroactive coating on an electrode. Corrosion protection provided by an impermeable, non-electroactive barrier such as microporous silica is a significant application, but the present review is focused on electroanalytical applications where the ability to transfer charge and/or provide pathways for analytes is required. With mesoporous silica sol-gel films, diffusion to the underlying electrode surface can occur to some extent, but for electroanalytical applications, enhancing transport is advantageous. Such enhancement can occur by two routes. First, the sol (hence, the film that is fabricated) can be doped with a redox system capable of charge transport by site-to-site electron self-exchange. Generally, the dopant also serves as a catalyst by mediation of electron transfer with the targeted species in the sample phase (analyte). Second, channels can be templated through the film so that the analyte can diffuse to the base electrode. Practically, these channels are in the nanometer diameter range. The approach employed is dependent upon the method of film formation; common ones are summarized below.

\section{Formation of catalytic silica sol-gel films with a con- tinuous structure on electrodes}

Historically, the formation of continuous sol-gel films on electrodes is performed by dip-coating, pipetting/drying, or pipetting/spin-coating the precursor sol onto the electrode surface $[8,12-14]$. Analytical applications of electrodes modified with such sol-gel films primarily have merit if they resist loss of activity by adsorption of matrix components or products of the electrochemical reaction and/or host a catalyst for electrochemical reaction with the analyte. The films must conduct charge for voltammetric application, which precludes use of microporous films unless a secondary step in sol-gel processing obviates the passivating property. For example, inclusion of a surfactant in the sol can enhance performance by formation of mesopores from the surfactant organizing into micelles during the gelation and drying steps.

A related approach is to use templates to prepare the film with an array or ensemble of nanoscale pores as a direct link between the sample phase and the base electrode. With such pores, the sol-gel film can serve as a size-exclusion phase (thereby resisting passivation by macromolecules in the sample) and can promote hemispherical diffusion of the analyte to the nanopores as the current-limiting step, which improves the ratio of the analytical signal to the background. This approach is detailed in the "Applications of sol-gel modified electrodes" section.

Inclusion of a catalyst in sol-gel films by doping the sol is exemplified by using Co ${ }^{\text {II }}$ tetrakisphenylporphyrin as a dopant in a TEOS (tetraethoxysilane) sol [15]. By acid catalysis and pipetting an aliquot onto glassy carbon, a continuous film was formed that catalyzed the oxidation of dopamine. Apparently, the microporous nature of the film had conductivity imparted exclusively by electron self-exchange of the $\mathrm{Co}^{\mathrm{II}} / \mathrm{Co}^{\mathrm{III}}$ couple. In a recent example, Olívio et al. [16] immobilized phosphomolybdic acid (PMA) in ormosils derived from a $\mathrm{R}^{\prime}$ Si(alkoxy) $)_{3}$ sol where $R^{\prime}$ was either APTES (aminopropyltriethoxysilane), 3-cyanopropyl, or 3-glycidyl. With the 3-cyanopropyl as the side chain, PMA mediated the reduction of ametryn and provided conductivity by electron self-exchange. In contrast, a polyoxometalate catalyst was added to a TEOS sol that also contained a surfactant [17]. The sol was pipetted onto a Pt electrode and used, after gelation, for the reduction of hydrogen peroxide. Even with acid catalysis of the sol-gel processing, a mesoporous film probably formed because of the surfactant, thereby augmenting the conductivity related to electron self-exchange. In an alternative method for adding a catalyst, an electrode for oxygen reduction was prepared with inclusion of hemoglobin $(\mathrm{Hb})$ in a base-catalyzed TEOS-derived sol-gel [18]. The film was prepared by first coating carbon paste with $\mathrm{Hb}$ and, second, pipetting the sol onto this modified surface. The combination of mesoporosity obtained via base-catalyzed gelation 
and the order of addition of the components apparently resulted in a film that that was catalytic because of the $\mathrm{Hb}$ layer and conductive via electrolyte diffusion through the mesoporous sol-gel.

A significant advance in modifying electrodes with a sol-gel film was the development of electrochemically assisted modification of electrode surfaces by Mandler and coworkers [19-21]. Applying a negative potential to an electrode in a sol results in generation of $\mathrm{OH}^{-}$, which in turn catalyzes the formation of a mesoporous film of silica when the precursor is, for example, tetramethylorthosilicate (TMOS) or a related species [19]. In an analogous manner, acid-catalyzed sol-gel processing occurs with application of a positive potential where hydronium ion is generated, which they demonstrated by sol-gel deposition of microporous silica from a methyltrimethoxysilane precursor. This methodology is suited to deposition of other sol-gels such as zirconia and titania [20,21]. Electrochemically assisted deposition is particularly useful because it readily enables control of the film thickness by selection of the applied potential and the deposition time. One result is that by using acid-catalyzed processing to obtain microporous silica, a passivating film can be obtained at a sufficiently long deposition time (Fig. 1). Although such films find application in corrosion protection, for electroanalytical studies, a conducting surface is needed. The next section reviews development of films with pores of a selected diameter within the general range 1-50 nm. These studies have been performed in parallel with the use of the abovedescribed [19-21] electrochemically assisted deposition of sol-gel films on electrodes.

\section{Formation of nanoporous sol-gel films on electrodes}

Commonly, mesoporosity of sol-gels has been accomplished through use of surfactants that form micelles during the gelation process. Such use of surfactants traces to studies on the synthesis of zeolites. For example, the combination of tetraethoxysilane (TEOS) and a bolaamphiphile surfactant was shown to serve as a precursor to a sol-gel monolith with pore sizes in the range 2.0 $2.7 \mathrm{~nm}$ [25]. Such studies were directly transferrable to the formation of mesoporous films on electrodes. An important advance was to combine inclusion of a surfactant with electrochemically assisted sol-gel formation (EASA). In the method, Walcarius and coworkers [26] combined the inclusion of cetyl trimethylammonium bromide (CTAB) in a TEOS sol with electrochemically assisted organization of micelles in a sol film on the electrode; the gelation was catalyzed by cathodic generation of $\mathrm{OH}^{-}$. The combination of the applied electrical field and the growth of the film outward from the electrode overcame the tendency of formation of surfactant assemblies to orient parallel to the substrate surface. Regarding the catalysis of sol-gel processing, various working electrodes were inserted into the stable, $\mathrm{pH} 3$ sol, and the potential was adjusted to a value at which $\mathrm{OH}^{-}$ was generated. The CTAB was organized into stacks perpendicular to the electrode surface as the sol-gel formation occurred.
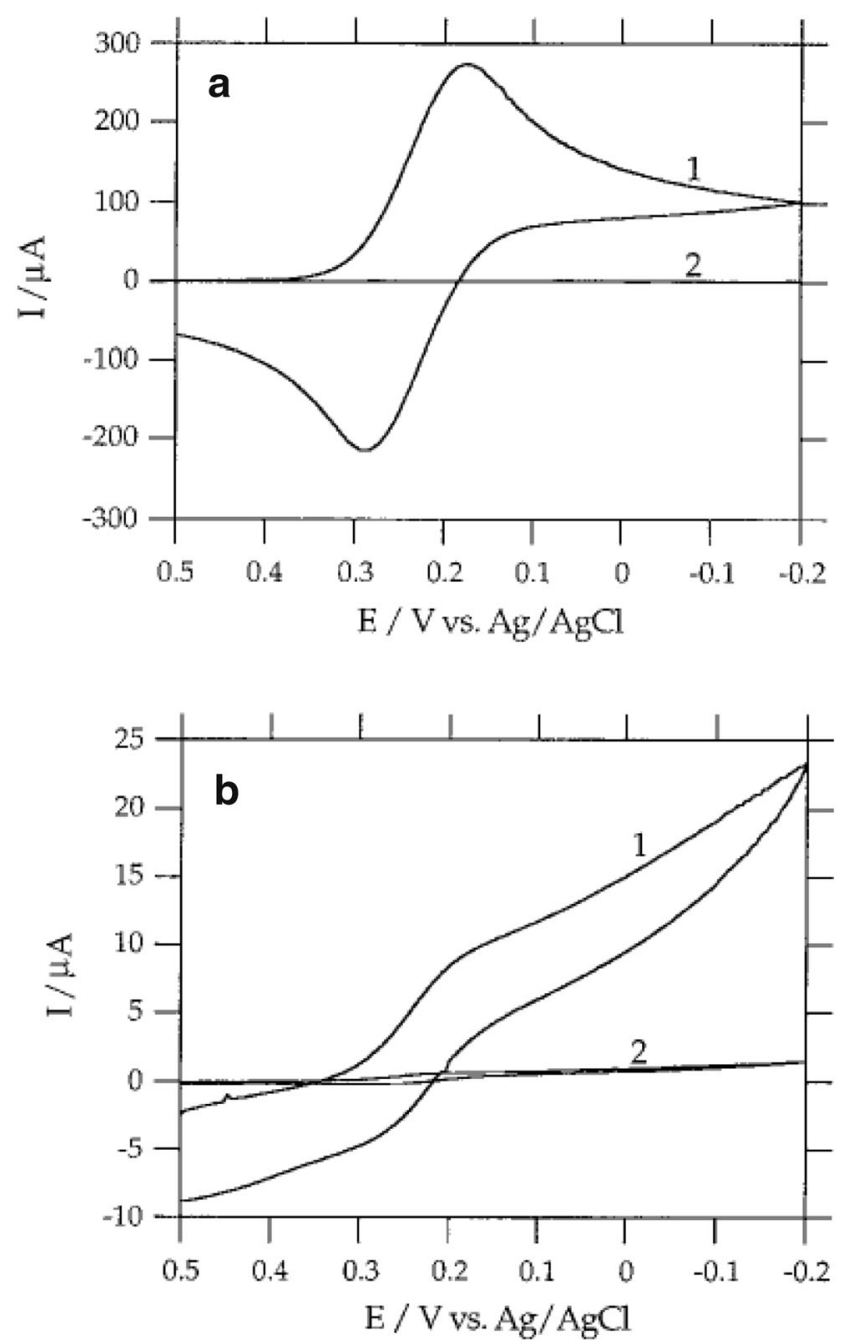

Fig. 1 Cyclic voltammetry of $2 \mathrm{mmol} \mathrm{dm}^{-3} \mathrm{Fe}(\mathrm{CN})_{6}{ }^{3-}$ in $0.1 \mathrm{~mol} \mathrm{dm}^{-3}$ $\mathrm{KCl}$ at an ITO electrode modified with an ormosil film deposited by an electrochemically assisted process from a precursor comprising MeTMOS, ethanol, water, $\mathrm{KNO}_{3}$, and a $1 \mathrm{mmol} \mathrm{dm}^{-3}$ phthalate buffer at $\mathrm{pH}$ 3.5. A - before (1) and after (2) application of - $1.1 \mathrm{~V}$ vs $\mathrm{Ag} \mid \mathrm{AgCl}$ for $30 \mathrm{~min}$ in the precursor solution; B-after applying the potential for (1) $5 \mathrm{~min}$ and (2) $30 \mathrm{~min}$. Reprinted with permission from Shacham et al. [19] (Fig. 6)

Upon drying and removal of the CTAB, films with thicknesses on the order of $50-100 \mathrm{~nm}$ (depending of the time of $\mathrm{OH}^{-}$ generation) with an ordered hexagonal array of mesopores were obtained. Voltammetry verified that the diffusion coefficients of ruthenium hexamine and ferrocene ethanol were comparable with those obtained at a bare electrode in an aqueous electrolyte. A variation of the method changed the pore volume from hydrophilic to hydrophobic [27]. With a precursor sol comprising a mixture of TEOS and octyltrimethoxysilane or hexadecyltrimethoxyl silane, the typically hydrophilic pores became hydrophobic, thereby influencing the relative diffusion rates of a charged (ruthenium bipyridine) and a neutral (ferrocene dimethanol) species. 
Characteristics of stacked cyclodextrin (CD) led to its use in templating pores perpendicular to the surface in sol-gel films. The truncated-cone structure of CD leads to an inner channel of such stacks. Ohira et al. [23] hypothesized formation of wormlike stacks of $\mathrm{CD}$ on an $\mathrm{Au}(\mathrm{III})$ surface in an aqueous perchlorate solution (Fig. 2). Depending on the potential of the $\mathrm{Au}(\mathrm{III})$ surface, the primary state of the $\mathrm{CD}$ was: (a) desorbed (more negative than $-0.6 \mathrm{~V}$ ), (b) organized into nanotubes perpendicular to the surface $(-.1 \mathrm{~V}$ to $-0.5 \mathrm{~V})$, or (c) a disordered adlayer (positive of $-0.1 \mathrm{~V}$ ). This supposition was supported by scanning tunneling microscopy imaging. The formation of CD stacks in a TMOS sol also was used in the formation of porous monoliths where pore sizes were controlled over the range $1.5-2.0 \mathrm{~nm}$, depending on the specific CD that was used [28].

The inclusion of stacked $\beta-C D$ in a microporous sol-gel film derived from a TEOS precursor and deposited by electrochemically assisted, acid-catalyzed processing [19-21] enhanced electroanalytical determinations at this modified electrode [22]. In the absence of $\beta-C D$, such films are passivating. When the film was formed in the presence of $\beta-C D$ on gold or indium tin oxide, it supported quasi-reversible cyclic voltammetry of a test species, ferrocene. Of importance is that the molecular size of the ferrocene is smaller than the $0.7 \mathrm{~nm}$ core-diameter of the $\beta$-CD used, which enables diffusion through the pores presumably perpendicular to the electrode surface. It was also shown that the pores can be modified to contain an electron-transfer mediator [29]. Continuous cyclic voltammetry of a $\mathrm{CoCl}_{2}, \mathrm{~K}_{3} \mathrm{Fe}(\mathrm{CN})_{6}$ mixture at this film initially formed cobalt hexacyanoferrate $(\mathrm{CoHCF})$ in the 0.7 nm pores. With continued cycling, bulk CoHCF material was deposited over the top of the silica film. The structure of the $\mathrm{CoHCF}$ that was deposited in the pores differed from that of the bulk material, as shown by its cyclic voltammetry signature. This steric effect on the nature of the CoHCF produced was supported by X-ray imaging and infrared spectroscopy [29].

The formation of macroporous silica films on electrodes derived from TMOS was accomplished by inclusion of poly(styrene) sulfonate (PSS) beads in the sol [30, 31]. The PSS was added to the sol, and the aged mixture was spin-coated onto a glassy carbon electrode GCE). After gelation, the PSS was dissolved with chloroform and the resulting structure characterized. The voids formed upon PSS removal constituted pores that extended through the film. Electrochemistry and atomic force microscopy were used to characterize the films, yielding approximate dimensions of 10-nm diameter contact areas of circular pores at the GCE surface and 100-nm diameter openings at the outer plane of the silica film. Deposition of $\mathrm{Cu}$ in the resulting pores resulted in a nanoarray of electrodes with a distribution reflecting the organization of the PSS during gelation [31].

An advantage of the use of PSS added to the sol over CDtemplating is the greater range of pore size that can be attained; however, the resulting pores can be tortuous as well as cylinders perpendicular to the electrode surface. A two-step method was developed to achieve a range of pore diameter while limiting pores to cylinders perpendicular to the electrode surface. The first step was to adsorb "islands" of moieties on the electrode that increase locally the overpotential of $\mathrm{H}^{+}$generation. Second, the electrode with submonolayer coverage of these islands was immersed in a sol, and electrochemically assisted processing of gelation was performed. As a result, catalysis of sol-gel processing by $\mathrm{H}^{+}$occurred only where these islands were absent $[32,33]$. Acid catalysis results in linear chains of -Si-O- [12], which in this case grow out from the electrode surface. With the assumption that these chains do not crosslink or intertwine in the space above the islands, a hypothesis can be made that a distribution of nanopores perpendicular to the electrode surface will form.
Fig. 2 Representation of the adsorption of $\beta$-cyclodextrin as a function of potential applied to a $\mathrm{Au}(\mathrm{III})$ surface. Reprinted with permission from Ohira et al. [23] (Fig. 3)

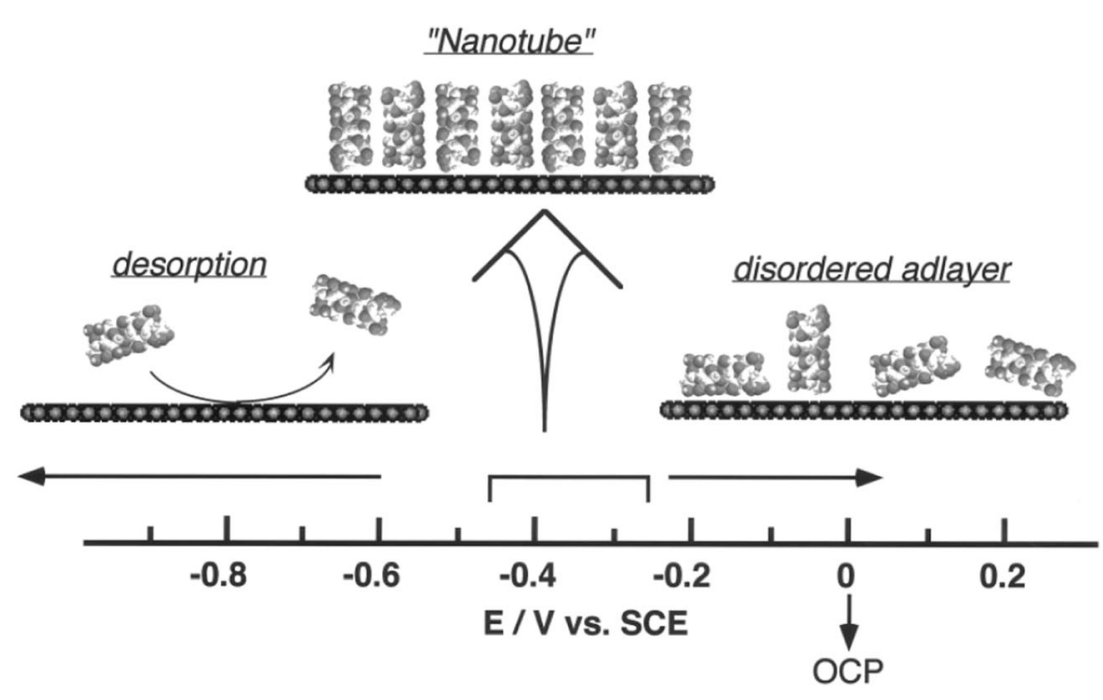


A candidate for such a templating agent based on its distribution on a surface under conditions of sub-monolayer coverage is the family of poly(amidoamine) dendrimers (PAMAM) of various generations $[24,34,35]$. A representative illustration of the adsorption of PAMAM is shown in Fig. 3.

An initial test of the above hypothesis was performed in which G4-PAMAM was adsorbed from the sol rather than pre-adsorbed to the electrode. The electrode modification was by electrochemically assisted gelation [34]. An oxygen plasma was used to eliminate the dendrimer from the film. Scanning electron microscopy showed a random distribution of $10 \pm 5 \mathrm{~nm}$ pores, a value larger than the calculated $4.5 \mathrm{~nm}$ diameter of G4-PAMAM. Given that clustering of the dendrimers can occur with this preparation procedure, the result does not constitute a negative test of the hypothesis; moreover, the film formed from a G4-PAMAM containing sol may involve tortuous mesopores in addition to the desired structure.

A more direct test of the above hypothesis was by depositing the film on an electrode that was pretreated by binding a sub-monolayer distribution of PSS nanobeads to its surface [32, 33, 36, 37]. Initially, a sub-monolayer of APTES was adsorbed. The use of adsorbed APTES is well known for anchoring anions to electrode surfaces [38-41]. Next, PSS was bound to the APTES sites. Figure 4 illustrates the influence of a sub-monolayer of APTES on the modification of indium tin oxide (ITO) by $20-\mathrm{nm}$ PSS beads [40]. Subsequent deposition of an ormosil by an electrochemically assisted process $[23,25,26]$ with a trimethylmethoxysilane precursor resulted in a film with 20 -nm pores that were separated by ca. $100 \mathrm{~nm}$. The diameter of the pores matched that of the PSS, and the pore separation is consistent with the PSS distribution (Fig. 4). These are positive tests of the above hypothesis. These data suggest that the nanopores are perpendicular to the electrode surface. In addition, transmission electron spectroscopy of a cross-section of the ormosil film gave images in agreement with the model [33]. Further evidence of the cylindrical shape was obtained by layer-by-layer assembly of $\mathrm{RuOCN}$ and $\mathrm{ZrO}_{2}$ in 50-nm pores [36] where $\mathrm{RuOCN}$ is mixed-valent ruthenium oxide with oxycyano crosslinks that is electrochemically synthesized by cyclic voltammetry of a $\mathrm{K}_{4} \mathrm{Ru}(\mathrm{CN})_{6}, \mathrm{RuCl}_{3}$ mixture [42]. The current increased in
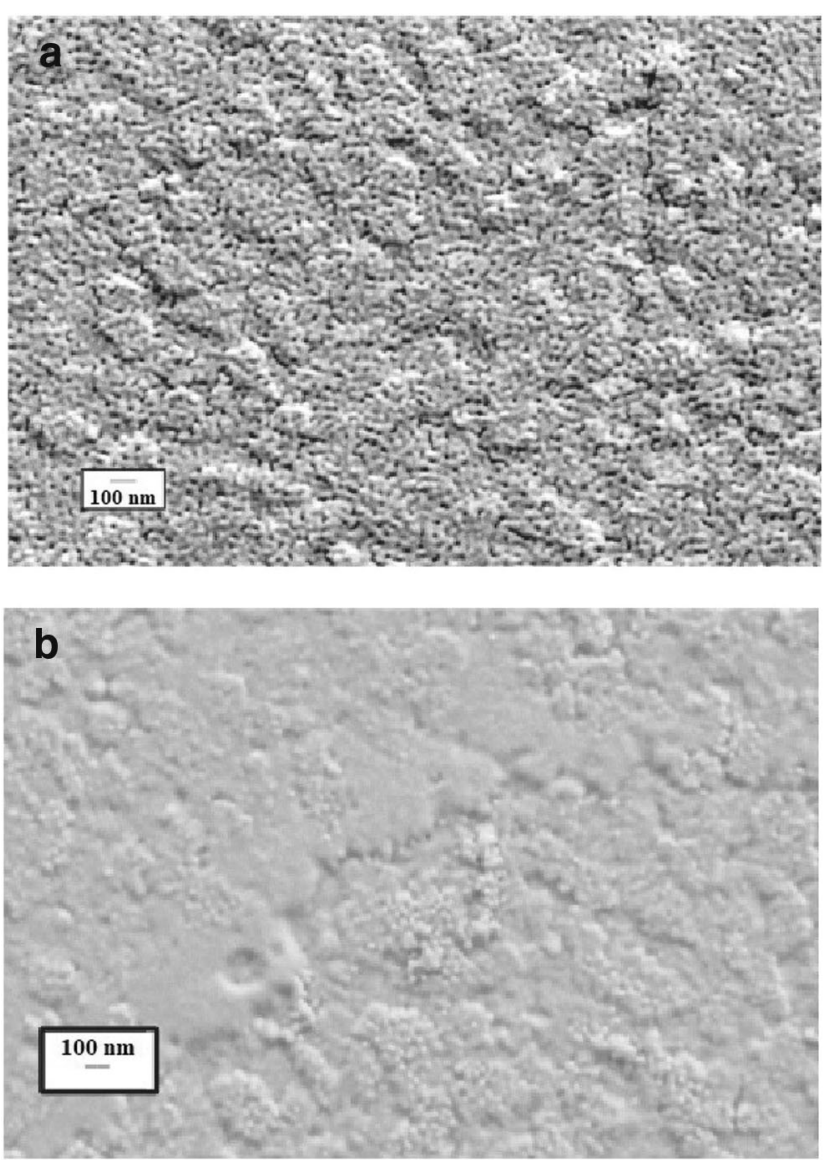

Fig. 4 SEM image of an ITO electrode surface after immersion in a 20$\mathrm{nm}$ PSS suspension. a The ITO was modified by a $15 \mathrm{~min}$ exposure to $0.5 \mathrm{mmol} \mathrm{dm}{ }^{-3}$ APTES solution. b Image of pristine ITO. Reprinted with permission from Ciabocco et al. [33] (Fig. 1)

direct proportion to the number of layers, which signifies a cross-sectional area that is independent of the vertical position along the pore, i.e., the areas of the pore cross-sections are independent of their position along the length of the pore.

Electrochemical investigation of this nanopore array was done by comparison with studies by White and coworkers on mass transfer to the base of a single nanopore [43, 44]. Cyclic voltammetry of $1.0 \mathrm{mmol} \mathrm{dm}{ }^{-3} \mathrm{Ru}(\mathrm{CN})_{6}{ }^{4-}$ in $1.0 \mathrm{~mol} \mathrm{dm}^{-3}$ $\mathrm{KCl}$ showed radial diffusion as the current limiting factor at scan rates below $5 \mathrm{mV} \mathrm{s}^{-1}$, which was expected for the
Fig. 3 Tapping mode atomic force microscopy of generation-4 PAMAM on mica from a $0.1 \%$ and b $0.01 \%(w / w$ in distilled water). Reprinted with permission from Tomalia and coworkers [24] (Fig. 1)
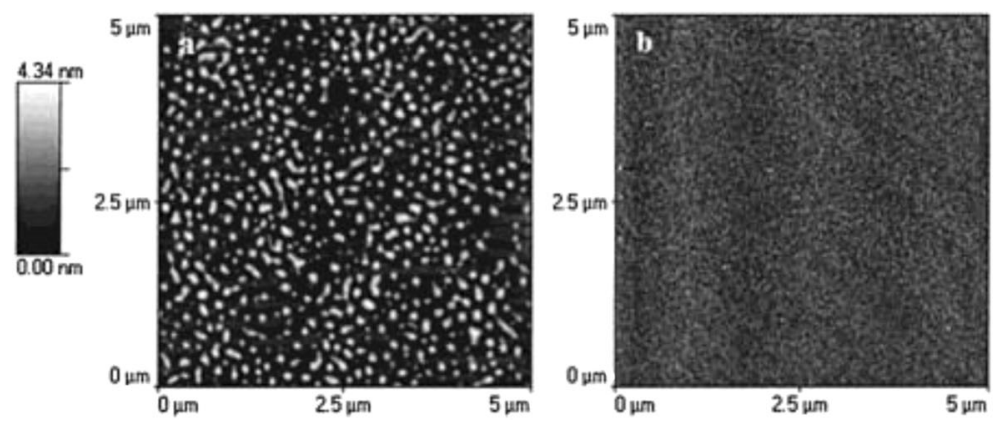

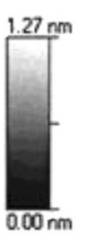


thickness (pore depth), ca. $200 \mathrm{~nm}$, of the film [33], i.e., the time for diffusion down the pore for a species with a diffusion coefficient of $10^{-6} \mathrm{~cm}^{2} \mathrm{~s}^{-1}$ is not a factor in limiting the current in this scan rate range. These and related results suggest potential utility of this method of fabricating a nanopore array. Pore density is readily varied by altering conditions of APTES adsorption. Film thicknesses in the 20-200 nm range are commonly achieved by varying the electrochemical deposition of sol-gels or ormosils, and pore diameters can be controlled in accord with the size of the PSS nanobeads or the use of alternative templates such as $C D$ s and various generations of PAMAM. Applicability needs to be investigated relative to other means of fabricating nanoarrays such as ion milling [45], aluminum oxide films [46], noble metal modification of aluminum oxide films [47-49], and screen-printed titania [50].

Sol-gel chemistry in combination with initial modification of a surface with a bilayer was used to fabricate a macroporous film. In sequence, layers of, first, $1200 \mathrm{~nm}$ silica particles and, second, $500 \mathrm{~nm}$ silica particles were deposited; $\mathrm{Au}$ and $\mathrm{Pt}$ were deposited to a depth corresponding to the order of the particulate layers; TEOS was deposited using electrochemically generated $\mathrm{OH}^{-}$as the catalyst; and the initial templating particles were removed [51]. Further modification of the resulting structure may result in a surface that shares properties with nanoporous sol-gel arrays.

\section{Electrodes based on sol-gel composites}

Silica in the form of sub-microparticles or as a binder in combination with carbon nanoparticles or nanotubes comprises a means of fabricating a composite related to sol-gel films. Fabrication with sol-gel binders traces to studies by Lev and coworkers that showed a stability advantage over similar systems such as carbon paste electrodes [52]. Such composites share some attributes with the films described above. Especially when one component is functionalized, these materials can serve as hosts for catalysts, including enzymes. In a typical example, Bachas and coworkers [53] utilized the conductivity of carbon nanotubes and the ability to immobilize amino acid oxidase to fabricate an electrochemical biosensor with a sol-gel matrix. The released $\mathrm{H}_{2} \mathrm{O}_{2}$ was detected at the carbon nanotubes. Long-term stability was the primary attribute of this design. A related design for a sorbitol biosensor immobilized both the enzyme and its cofactor [54]; the signal was from the oxidation of NADH using poly(methylene green) as a mediator. Walcarius and coworkers [55] prepared a biosensor for glucose that incorporated the following in a sol-gel: carbon nanotubes to which vitamin $\mathrm{K}_{3}$ was adsorbed, polyethyleneimine (PEI), $\beta$-nicotinamide adenine dinucleotide, and glucose dehydrogenase. The amperometric response under potentiostatic conditions was linear over the range 1$11 \mathrm{mmol} \mathrm{dm}^{-3}$. Generally speaking, the inclusion of PEI can be significant in terms of stability in that sol-gels deactivate certain classes of enzyme [56].

There are numerous examples of these composites that do not involve enzymes. For example, using a TEOS-derived solgel as a binder, a composite that included carbon nanotubes and gold nanoparticles comprised an electrode suited for determinations of dopamine and ascorbic acid, alone and in mixtures [57]. In some cases, these composites function as standalone working electrodes rather than modifiers. An example is an electrode made by adding nickel powder and graphite to methyltrimethoxysilane that was subsequently processed in a tube; it was applied to the oxidation of cystine, cysteine, and methionine [58]. Recently, an electrode was prepared from mercaptopropyl-methyldimethoxysilane, graphite powder, gold nanoparticles, and carbon nanotubes [59]; it was used for the differential pulse voltammetry of uric acid, xanthine, and caffeine. Detection limits in the range $50-100 \mathrm{nmol} \mathrm{dm}^{-3}$ were obtained.

Particulate silica prepared by sol-gel processing has been used to modify electrodes, especially using layer-by-layer electrostatic assembly (LbL). Using the opposite charges of silica and of carbon when it is functionalized with an amine, an electrode was modified by the LbL method [60]. A related assembly used particulate silica prepared by sol-gel processing in the presence of an ionic liquid and sulfonated carbon nanoparticles [61]. This modified electrode also included laccase thereby comprising a biosensor in which its high porosity led to increased sensitivity was additional layer numbers. Opallo and coworkers also used LbL assembly to fabricate a biosensor based on immobilized bilirubin oxidase [62] and to incorporate gold nanoparticles on electrodes used for determinations of nitrite, sulfite, and hydrazine [63]. Overall, the LbL method involving particulate silica is potentially suited to a wide range of applications in that it comprises a highly porous spacer in these assemblies.

\section{Influence of surface charge on nanoporous silane- based films}

Subject to the composition of the solvent, silica sol-gels generally are stable in aqueous solution although at $\mathrm{pH}>8$ or $\mathrm{pH}$ $<2$, the rate of dissolution becomes significant [12]. Within this range, sol-gels synthesized from alkoxides such as TEOS and TMOS have the acid-base properties of silica, i.e., unless they are in contact with an acidic solution, they are anionic. Electrochemical applications of both films and monoliths are, therefore, strongly dependent upon $\mathrm{pH}$ when the species involved are ionic. This point is illustrated by the cyclic voltammetry of $\mathrm{Fe}(\mathrm{CN})_{6}{ }^{3-}$ and of $\mathrm{Ru}\left(\mathrm{NH}_{3}\right)_{6}{ }^{3+}$ in neutral $\mathrm{KCl}$ electrolytes of varying ionic strength (Fig. 5) [64]. At the lower ionic strengths, the voltammetric current is suppressed by the repulsion effect of the negative charge of silica on $\mathrm{Fe}(\mathrm{CN})_{6}{ }^{3-}$; increasing the ionic strength shields the 


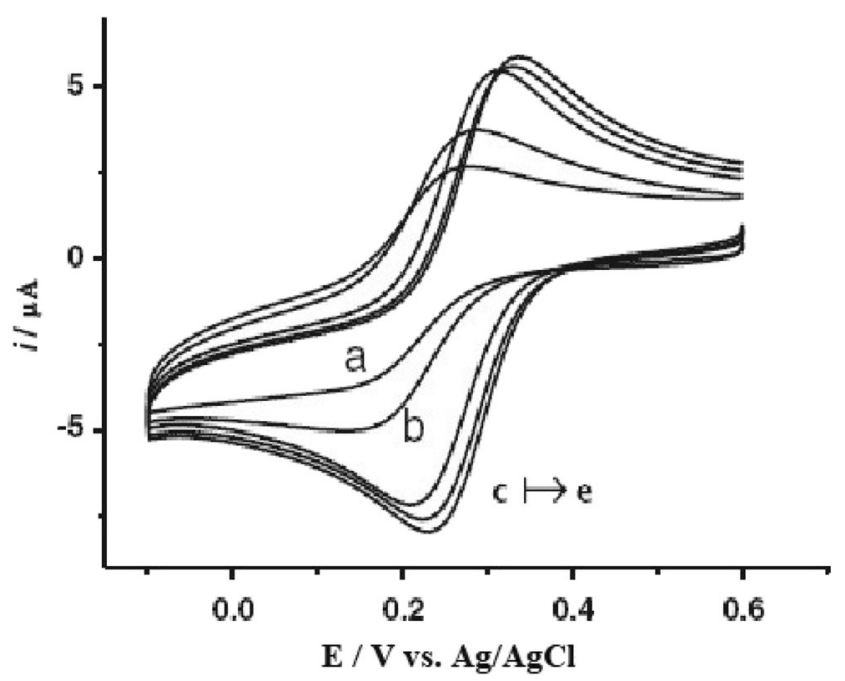

Fig. 5 Influence of ionic strength of the cyclic voltammetry of $1.0 \mathrm{mmol} \mathrm{dm}{ }^{-3} \mathrm{Fe}(\mathrm{CN})_{6}{ }^{3-}$ in neutral solution. The electrode is glassy carbon coated with a sol-gel film electrochemically deposited from TEOS with templated $10-\mathrm{nm}$ pores. $\mathrm{KCl}$ concentrations $\left(\mathrm{mol} \mathrm{dm}^{-3}\right)$ : a, 0.05 ; b, 0.10; c, 1.0; d, 1.5; e, 2.0. Scan rate, $50 \mathrm{mV} \mathrm{s}^{-1}$. Reprinted with permission from Cox et al. [64] (Fig. 4)

$\mathrm{Fe}(\mathrm{CN})_{6}{ }^{3-}$ from the negative sites on the sol-gel. The opposite trend is observed with $\mathrm{Ru}\left(\mathrm{NH}_{3}\right)_{6}{ }^{3+}$ where preconcentration by ion exchange on the silica is observed at the lower ionic strengths.

There are two approaches to alleviating the influence of charge. Using one that is common in liquid chromatography, end-capping the silica with methyl groups [65] eliminated the influence of $\mathrm{pH}$ and ionic strength [64]. The second method is to use as the sol a trialkylalkoxysilane so that the product is an ormosil without charged groups [32]. In general, the selection of components from which to synthesize ormosils can have a marked influence on their properties. The simplest case is to

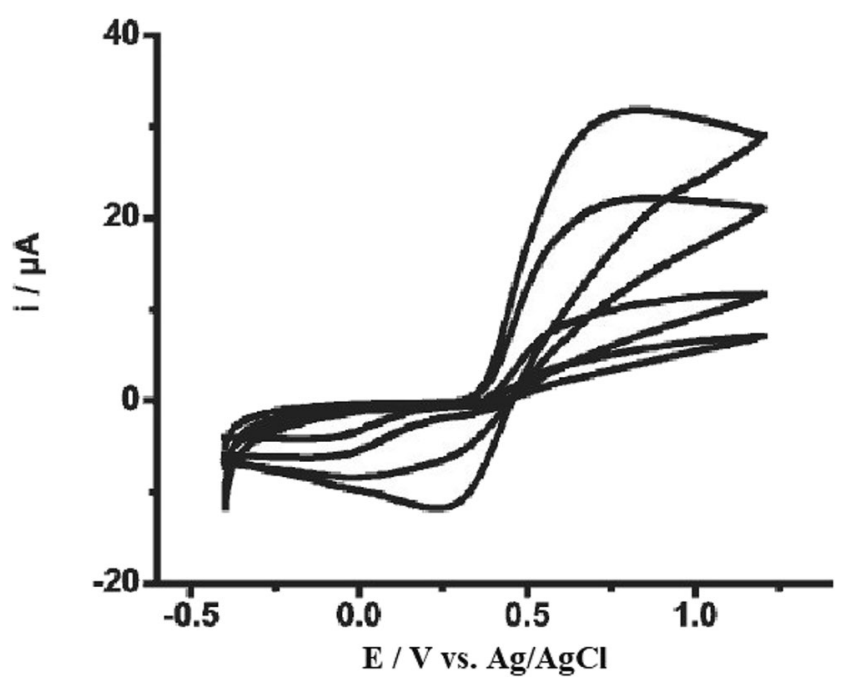

Fig. 6 Cyclic voltammetry of $5.0 \mathrm{mmol} \mathrm{dm}^{-3}$ ferrocene at ITO coated with CD-templated silica. Scan rates: 4 (innermost trace), 6, 8, and 10 (outermost trace) $\mathrm{mV} \mathrm{s}^{-1}$. Electrolyte, $0.1 \mathrm{~mol} \mathrm{dm}^{-3} \mathrm{Bu}_{4} \mathrm{NClO}_{4}$ in acetonitrile. Reprinted with permission from Wandstrat el al. [22] (Fig. 2) process an ormosil from a trialkylalkoxysilane sol, as mentioned above. The resulting neutral framework can then take on properties determined by other additives, for example, by templating nanoporosity and/or incorporating active components in the matrix. Partial replacement of the alkoxyl group of $\mathrm{RO}_{4} \mathrm{Si}$ with a non-oxo organic group (i.e., $\mathrm{R}_{4-\mathrm{n}}^{\prime} \mathrm{RO}_{\mathrm{n}} \mathrm{Si}$ where $n \leq 4)$ has utility. An example is a dip-cast ormosil processed from dimethyldimethoxysilane [66]; the residual negative sites can assist in impregnating the film with $\mathrm{Ru}(\mathrm{bpy})_{3}{ }^{2+}$. The $\mathrm{Ru}(\mathrm{bpy})_{3}{ }^{2+}$ served a dual purpose. For the electrochemical process, it acted as a site-to-site charge carrier; in addition, it generated the luminescence signal employed in the analytical application. In a more recent example, Walcarius and coworkers introduced chains that imparted hydrophobic properties to the pores in an ormosil film, as described in the "Formation of nanoporous sol-gel films on electrodes" section [27].

\section{Applications of sol-gel modified electrodes}

As described in reviews [1-11,67], electrochemical sensors based on sol-gel modified electrodes have benefitted from synthetic procedures that imparted ordered mesoporosity. One reason why this characteristic is important for analytical applications is that it can provide resistance to fouling from adsorption (to the sites of electron transfer) of passivating macromolecules that may be components of real-world samples. To evaluate the efficacy of such films for alleviating passivation, we investigated the influence of model fouling agents, phospholipids (PLs), on the cyclic-voltammetry of $\mathrm{Fe}(\mathrm{CN})_{6}{ }^{3-}$. Peak currents, $\mathrm{i}_{\mathrm{p}}$, for the reduction of $\mathrm{Fe}(\mathrm{CN})_{6}{ }^{3-}$ at a bare electrode and one modified with templated pores in an ormosil film were compared [32]. The PL was not electroactive under the conditions used. With the PL absent, $i_{\mathrm{p}}$ was $10.8 \pm 0.2 \mu \mathrm{A}$ at an electrode coated with an ormosil with templated $10-\mathrm{nm}$ pores; under the same voltammetric conditions, the presence of $300 \mu \mathrm{mol} \mathrm{dm}{ }^{-3}$ PL yields a statistically identical value, $10.6 \pm 0.2 \mu \mathrm{A}$. The corresponding values at a bare electrode were $17.1 \mu \mathrm{A}$ and $7.5 \mu \mathrm{A}$ on the initial scan. With bovine serum albumin as the test interferent, comparable results were observed. Subsequently, the same general result was found by Serrano et al. at an electrode modified with a sol-gel film by EASA [68]. The cyclic voltammetric response of 5-100 $\mu \mathrm{mol} \mathrm{dm}{ }^{-3}$ propranolol was linear and not significantly affected by $5 \mu \mathrm{mol} \mathrm{dm}{ }^{-3}$ hemoglobin. With this electrode, a detection limit significantly below of $5 \mu \mathrm{mol} \mathrm{dm}{ }^{-3}$ propranolol can be expected with methodology such as pulse voltammetry or flow-injection amperometry. In a similar study with EASA fabrication of the silica film, access to the electrode surface by a $2.9-\mathrm{nm}$ electroactive dendrimer was blocked whereas the characteristic cyclic voltammogram of ferrocene was developed [69]. It is important to note that this separation of signals requires that 
the walls of the templated pores not get modified by a species that can transport charge by electron self-exchange [69]; in such a case, a voltammetric current from a physically blocked sample component can be developed. This class of interference by a size-excluded component is particularly significant when the negative sites of the silica can interact with a sample component. As route to minimize this process, both postgelation end-capping of the silica with methyl groups and using an ormosil precursor as the sol were shown to be effective $[32,64]$.

A templating agent that is analogous to a surfactant is stacked CD. With its characteristic open pore channels when stacked (The CD structure is one of a truncated cone), it has been shown to be well-suited to separation methods [70]. For pore formation in sol-gel films on electrodes, it overlaps EASA in terms of size domain $[22,26]$, but unlike a surfactant, CD does not influence the structure or strength of the bulk portion of the silica film [28, 71]. Cyclic voltammetry with these films shows the characteristics of current control by hemispherical diffusion (Fig. 5) [22], i.e., below ca. $5 \mathrm{mV} \mathrm{s}^{-1}$ a plateau is developed rather than a peak current. By codepositing dirhodium-11-phosphomolybdate in the electrochemically assisted gelation of TEOS [19-21], the mediated oxidation of phosphatidylcholine (PC) was promoted; a linear relationship between peak current and concentration developed over the range $1-100 \mu \mathrm{mol} \mathrm{dm}{ }^{-3} \mathrm{PC}$. In this example, the oxidation of PC occurs at the outer boundary of the film because the catalyst was a dopant in the silica phase; the pores functioned to facilitate charge transport to the supporting electrode.

Limitations of the use of surfactants and cyclodextrins as templates for nanoporous sol-gels are that they are useful only in the $0.7-2 \mathrm{~nm}$ size domain and that the pores are densely packed. While many applications are suited to these conditions, there is merit to dispersing the pores and increasing their diameter. For example, a larger pore diameter can accommodate a greater variety of catalysts attached to the base of the electrode, and by spacing the pores, hemispherical diffusion can be achieved at the sample/sol-gel interphase without overlap of the depleted region in the sample phase. To illustrate [72], a glassy carbon electrode was modified by adsorption of generation-4 PAMAM and using electrochemically assisted processing of a nanoporous film from a TEOS precursor. The PAMAM was eliminated with an oxygen plasma. Based upon further study [73], the pore size was ca. $10 \mathrm{~nm}$. Cyclic voltammetry of 5-hydroxytryptophan (HTPP) at a bare electrode resulted in formation of a passivating polymeric film, whereas at the electrode coated with a nanoporous silica film, the product identified by mass spectrometry was a dimer that did not passivate the surface. Using this electrode as the sensor in a flow-injection analysis system, a detection limit $(k=3$ criterion) of $17 \mathrm{nmol} \mathrm{dm}^{-3}$ was attained. A similar electrode was used for the electrocatalytic reduction of bromate and oxidation of methionine [73]. Here, the silica was endcapped [65] to eliminate its anionic sites, and gold nanoparticles modified with dirhodium phosphomolybdate (AuNP$\mathrm{Rh}_{2} \mathrm{PMo}$ ) [73] were bound to the pore-base electrode interface. The flow-injection analysis of bromate under potentiostatic conditions yielded a linear dynamic range of $0.2-10 \mu \mathrm{mol} \mathrm{dm}{ }^{-3}$ and a detection limit ( $k=3$ criterion) of $30 \mathrm{nmol} \mathrm{dm}^{-3}$.

The pore size range was increased by using PSS nanobeads as the template [32]. For example, 50-nm PSS beads were used in conjunction with deposition of an ormosil film by electrochemically assisted processing [19-21] using a trimethylmethoxysilane sol. The beads were removed by overnight dissolution in chloroform. As in the previous example [64], the AuNP- $\mathrm{Rh}_{2}$ PMo catalyst was bound by ionexchange to adsorbed APTES that was used to modify the exposed electrode area at the bases of the pores. When 10$\mathrm{nm}$ pores were templated, RuOCN was synthesized at the base of the pores by cyclic voltammetry of a $\mathrm{K}_{4} \mathrm{Ru}(\mathrm{CN})_{6}, \mathrm{RuCl}_{3}$ mixture [42]. This substance catalyzes the oxidation of species as diverse as $\mathrm{As}^{\mathrm{III}}$ and insulin a by combination of oxygen and electron transfer [74]. As a result, ionic species are often the product, which suggests the use of an ormosil or end-capping of a silica sol-gel to eliminate ion exchange. The oxidation of various biological compounds was promoted by these catalysts. With the $50-\mathrm{nm}$ pores, both $\mathrm{AuNP}-\mathrm{Rh}_{2} \mathrm{PMo}$ and RuOCN were suited as catalysts for the oxidation of cysteine (to cysteic acid) and of phospholipids, but with the 10-nm pores, the AuNP-Rh ${ }_{2}$ PMo was not applicable because of size. Demonstration of the analytical utility of such an electrode in a flow system is illustrated in Fig. 7 where PC is the analyte. Assuming that the peak current is proportional to concentrations below $10 \mu \mathrm{mol} \mathrm{dm}{ }^{-3}$, the calculated detection limit $(k=$ 3 criterion) is $0.6 \mu \mathrm{mol} \mathrm{PC} \mathrm{dm}{ }^{-3}$. With these ormosil films with templated cylindrical pores normal to the electrode surface, analytical utility as a detector in flow-injection analysis was demonstrated for the following combinations of analyte and mediator: cardiolipin, phosphatidylcholine, and cysteine (AuNP- $\mathrm{Rh}_{2} \mathrm{PMo}$ and $\mathrm{RuOCN}$ ); bromate (AuNP- $\mathrm{Rh}_{2} \mathrm{PMo}$ ); and $\mathrm{As}^{\mathrm{III}}$ (RuOCN) [32, 37]. Supporting the conclusion of analytical utility is that at scan rates, $v$, above that where hemispherical diffusion is a factor, the cyclic voltammetry peak currents are limited by linear diffusion. With cysteine as the test species, RuOCN as the catalyst, and $50-\mathrm{nm}$ the pore diameter, a plot of $\log i_{\mathrm{p}}$ vs $\log v$ over the range 10 $200 \mathrm{mV} \mathrm{s}^{-1}$ had a slope $=0.50$ and $R^{2}=0.999$.

With EASA [26] as the film deposition technique, a means of obtaining channels that accomplish both enhanced conductivity of silica films by electron self-exchange and catalytic activity by mediated electron transfer is to organize a dualfunction agent with the surfactant that templates the pores [75]. Such an active component, iron-triazole $\mathrm{Fe}(\mathrm{Htrz})_{3}$ was included with the TEOS and CTAB, from which a 
Fig. 7 Flow-injection

amperometry of

phosphatidylcholine (PC) at a glassy carbon electrode fabricated with an ormosil film with 50-nm pores. a AuNP- $\mathrm{Rh}_{2} \mathrm{PMo}$ and $\mathbf{b}$ RuOCN as the catalyst. Applied potential, $1.0 \mathrm{~V}$ vs SCE; supporting electrolyte, $0.25 \mathrm{~mol} \mathrm{dm}^{-3} \mathrm{Na}_{2} \mathrm{SO}_{4}$ at $\mathrm{pH} 2$; sample, $10 \mu \mathrm{mol} \mathrm{dm}{ }^{-3} \mathrm{PC}$.

Reprinted with permission from Mehdi et al. [32] (Fig. 9)

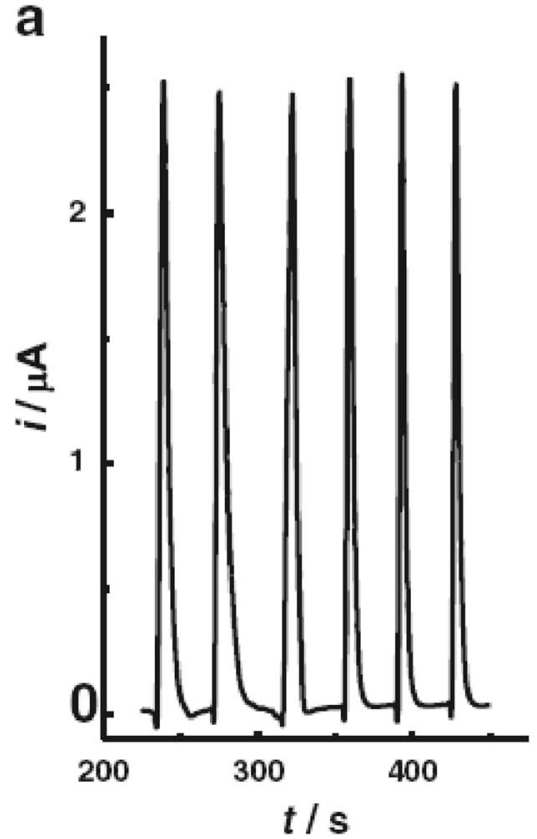

mesoporous film was deposited on the indium tin oxide base electrode. At an applied potential of $-1.3 \mathrm{~V}$, the basecatalyzed gelation was initiated along with vertically orienting CTAB micelles. The resulting pores contained tightly packed $\mathrm{Fe}(\mathrm{Htrz})_{3}$ that promoted conductivity based on efficient electron self-exchange. The reduction of hydrogen peroxide at the pore-sample interface occurred at $-0.4 \mathrm{~V}$. Flow-injection amperometry yielded a linear calibration curve over the range 5-300 $\mu \mathrm{mol} \mathrm{dm} \mathrm{dm}^{-3}$. This fabrication procedure undoubtedly results in an electrode with greater analytical performance than that achieved with the catalyst in the bulk phase of the film where the surfactant-templated pores primarily serve to lower the resistance to charge propagation. An electrode based on a TEOS-derived film using EASA was modified for the selective determination of cysteine in the presence of glutathione [76]. The film was subsequentially functionalized with ferrocene, thereby providing this analytical utility.

Another area of analytical application deals with imparting selective for analysis of biomolecules using molecular imprinting of sol-gels in conjunction with electrochemistry. In early studies, Collinson demonstrated the formation of a dopamine imprint in a sol-gel film, which provided a system for electrochemical distinction between dopamine and ascorbic acid [77, 78]. Recent studies often include nanoparticles in the formulation of the recognition film on an electrode. For example, Pd nanoparticles formed by reduction of $\mathrm{Pd}\left(\mathrm{Cl}_{4}\right)^{2-}$ with citric acid using poly(vinylpyridine) as a stabilizer were prepared and included in a sol-gel film processed to include norepinephrine (NE) as a templating agent [79]. Differential pulse voltammetry was used to remove the NE, which essentially activates the film. Using adsorption as a preconcentration step and differential pulse voltammetry to generate the signal, a detection limit of $0.1 \mu \mathrm{mol} \mathrm{NE} \mathrm{dm}^{-3}$ was attained. In a selectivity study, the response to NE was approximately twice that of the response to the same concentration of dopamine. A bilirubin-imprinted sol-gel was used to make 60-90 nm particles that were employed in a carbon paste electrode for a voltammetric determination with a limit of detection of $0.75 \mu \mathrm{mol} \mathrm{dm}{ }^{-3}$ [80]. A multistep process was used to prepare a sol-gel composite with gold nanoshells and an acetylsalicylic acid (ASA) template that was used for the voltammetric determination of ASA [81]. Nanoparticles dispersed in the film provided the enhanced conductivity that otherwise may limit application of films. Long-term stability is a potential problem that needs to be further explored.

\section{Sol-gels as solid electrolytes for electrochemical gas sensors}

Silica sol-gels that are processed to contain a liquid electrolyte can have physical properties of a solid while permitting facile diffusion of ions, i.e., diffusion coefficients on the order of $10^{-6} \mathrm{~cm}^{2} \mathrm{~s}^{-1}$ [82]. Therefore, by fabricating them in a configuration that hosts 2 - or 3-electrodes, the system comprises a stand-alone cell that serves as a sensor for gas-phase analytes. The process can involve partitioning of the analyte into the cell or protrusion of the working electrode into the gas phase. In the latter case, the electrochemical reaction occurs at the three-phase boundary among the sol-gel, working electrode, and gas phase. The most basic design [83] is to epoxy three electrodes into a glass tube so that they form a co-planar set of disks that are slightly recessed from the imaginary plane 
across the top of the tube. The sol-gel is then formed as a thin film that coats the electrode assembly.

In this example [83], a TEOS-derived sol-gel, which was processed to include $\mathrm{MgCl}_{2}$, coated the electrodes to function as the electrolyte. The $\mathrm{MgCl}_{2}$ was not only the supporting electrolyte but also an internal humidistat that maintained the water level of the sol-gel at ca. 30\%. The solid was formed by base catalysis of the sol-gel process. The inclusion of a surfactant in the sol resulted in a mesoporous material. The analytical determinations were by differential pulse voltammetry with the sensor used in the headspace over solutions of various concentrations of $\mathrm{H}_{2} \mathrm{O}_{2}$. Prior to voltammetry, the sensor was exposed to the gaseous atmosphere for varying times. A linear calibration curve was obtained over the range 96-5400 ppmv with a detection limit of $10 \mathrm{ppbv}$ using a 60 -min preconcentration [83]. For comparison, a Nafion-based diffusion scrubber with $1 \mathrm{mmol} \mathrm{dm}^{-3} \mathrm{HCl}$ as the receiving phase and a $\mathrm{Pt} / \mathrm{Rh}$ working electrode had a detection limit of 0.11 ppbv with a 9-min preconcentration [84]. The difference in detection limits probably reflected the greater efficiency of the diffusion scrubber.

Response time is an important factor for applications. One method to improve the response time of this general sensor design [83] was to employ a thinner sol-gel phase. In this regard, a significantly faster response time was achieved by using as the measurement system an interdigitated three electrode array that was coated with the gel formed from $5 \mu \mathrm{L}$ of surfactant-containing sol [85]. Analytical measurements were made by flow-injection amperometry with $\mathrm{Ar}$ as the carrier gas and $\mathrm{CO}$, which was injected with a syringe, as the analyte. The oxidation of $\mathrm{CO}$ at $0.8 \mathrm{~V}$ vs a Pt quasi-reference electrode provided the signal. The response and recovery times were sufficiently rapid to develop a peak on the current time plot. The detection limit was 5 ppmv. The flow system diluted the injection volume, so this limit was not because of the sensor but rather the associated delivery system. Of importance are that the sensor was stable for the 40-day period of the trial and the response was independent of humidity over the range 9$76 \%$. The behavior with respect to humidity was in marked contrast to similar designs but with Nafion rather than the solgel as the electrolyte [86].

An important design modification is to protrude the working electrode into the gas phase so that the electrochemical reaction occurs at the three-phase boundary, thereby eliminating the need for transfer of the analyte from the gas phase into the electrolyte. Based on this design, a detector for monomethyl hydrazine (MMH) was developed [87]. The working electrode was Pt modified with a film of RuOCN [42] that served as the catalyst for the oxidation of MMH. The response with this cell configuration was sufficiently fast to employ it as a detector in gas chromatography [88]. In a flow-injection analysis configuration, the characteristic response time, $\mathrm{T}_{90}$, was $5 \mathrm{~s}$ at a flow rate of $20 \mathrm{~mL} \mathrm{~min}^{-1}$, which is a much faster flow rate than that used in gas chromatography. When used as a detector in gas chromatography, the calibration curves were comparable with those of a flame ionization detector. A positive attribute of this amperometric detector is the ability to obtain a degree of separation of mixtures above that of the chromatographic column by control of the applied potential, as shown in Fig. 8.

The use of room-temperature ionic liquids (RTILs) as the electrolyte in electrochemical sensors is a recent advance in this field. Compton and coworkers [89, 90] demonstrated a membrane-free design where $2 \mu \mathrm{L}$ of RTIL formed a film over recessed microband electrodes. Cyclic voltammetry of $\mathrm{O}_{2}$ at various scan rates showed a reversible reduction to a superoxide with the RTIL electrolyte. A calibration curve using $\mathrm{O}_{2} / \mathrm{N}_{2}$ mixtures as samples gave a detection limit of $0.5 \% \mathrm{O}_{2}$. Using filter paper onto which electrodes were screen-printed, an electrochemical sensor for gaseous 1butanethiol was fabricated with a Co(II)phthalocyanine catalyst on the working electrode [91]. The filter paper was saturated with a RTIL. Flow-injection amperometry gave a linear

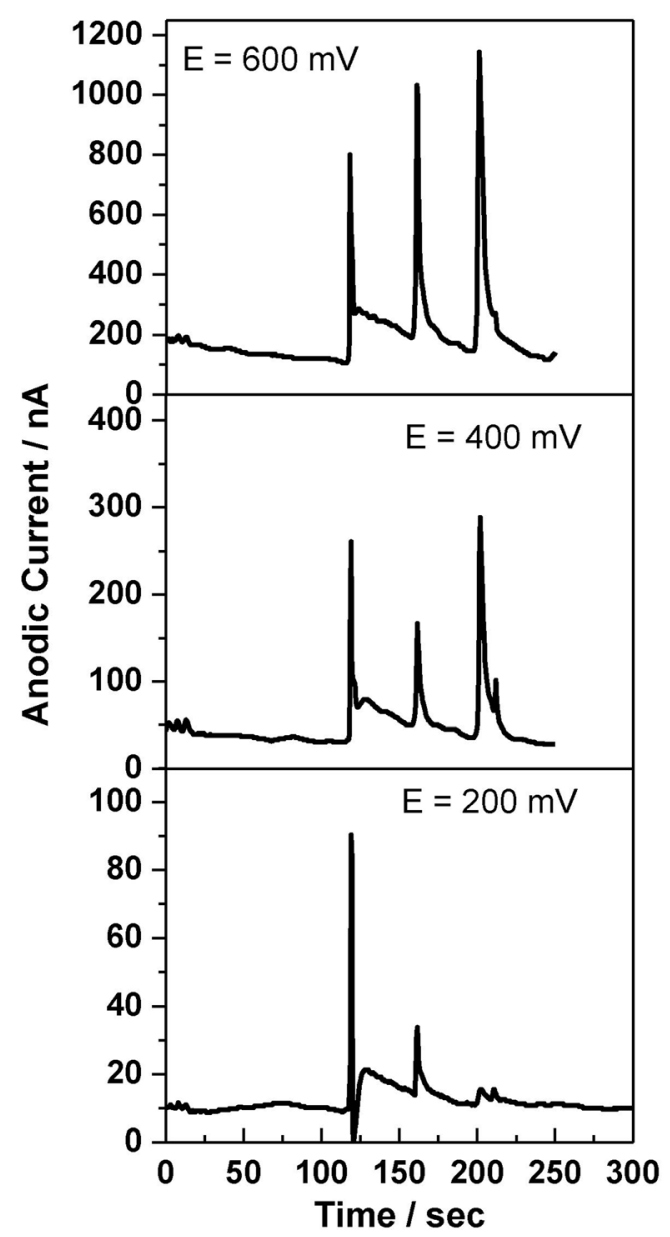

Fig. 8 Gas chromatography of (in elution order) 1,2-ethanedithiol, phenol, $p$-cresol, and thioanisole with the applied potential of the amperometric detector varied. Carrier gas, He; flow rate, $2.2 \mathrm{~mL} \mathrm{~min}^{-1}$. Reprinted with permission from Steinecker et al. [88] (Fig. 6) 
response over the range $2-200 \mu \mathrm{mol} \mathrm{dm}{ }^{-3}$ with a detection limit of $0.5 \mu \mathrm{mol} \mathrm{dm}{ }^{-3}$. It is especially significant that the peak half-width was only $6 \mathrm{~s}$, so 200 samples per hour were run.

A more traditional sensor design was one based on the Clark oxygen electrode. The primary design innovation was replacing the aqueous-based supporting electrolyte with a RTIL [92]. The resulting electrode gave a stable response to $\mathrm{O}_{2}$; the analytical current at $-1.2 \mathrm{~V}$ decreased by only $0.3 \%$ over a 60 -day test. The detection limit was 0.05 vol\%. The potential merits of this RTIL-based sensor included long-term stability.

The development of an electrochemical sensor based on a silica sol-gel framework and a RTIL electrolyte is suggested by the above studies. The synthesis of such a framework in a RTIL was demonstrated in a study not related directly to sensors [93]. Another result important to eventual amperometric sensor development was demonstration that mobility of species in ionic liquids confined in a silica framework matched that of their mobility as a bulk phase [94]. A study of conductivity of RTILs in silica provided the basis for use of this combination in various electrochemical devices [95]. Indeed, related materials have been applied to battery and fuel cell development, particularly as a part of a composite such as an ionic liquid confined in mesoporous silica that is mixed in a polymeric binder [96]. Also, related to possible sensor development is the design of proton exchange membranes based on silica and a RTIL [97]. A factor in the development of these devices is that RTILs can mitigate the problem of evaporation, which is especially important in sensors for microfluidic applications [98]. Small amounts of water did not change the response of a microelectrode to $\mathrm{O}_{2}$ in an RTIL [99] which further supports the future development of gas sensors based on silica frameworks and RTILs.

\section{Conclusions}

A significant advance in the use of silica sol-gels as a component in the modification of working electrodes is the templating of pores perpendicular to the electrode surface. One approach leads to empty nanowells of well-defined diameter connecting the sample to the base electrode. Their distribution and size depend on the species that is adsorbed prior to growing the film by an electrochemically assisted process. Several sizes can be achieved using commercially available materials such as various generations of PAMAM and sizes of PSS beads. Means of controlling the density of adsorbed PAMAM and of APTES, which is an anchor for PSS beads, are well documented. When the film that serves as the framework does not have acid-base properties because of endcapping the silica groups or using a sol that has only one alkoxy group on the $\mathrm{Si}$, a chemically passive nanowell is produced; hence, the charge, if any, on the electroactive species, does not cause departure from linear diffusion from the sample to the base of the pore. The nanowells can serve as reaction chambers where control of their diameters can influence the course of a chemical reaction coupled to the electrontransfer reaction. Therefore, the final product can be one that is different from that in an analogous bulk solution experiment. Unique chemical species, including catalysts, can be formed, which is an application that has only been explored in a few cases. Perhaps, more important, it can be envisioned that processes in biological membranes vs those in bulk cellular media can be mimicked. This characteristic is, of course, shared with other methods to prepare nanowells. In terms of electroanalysis, a diffuse array of nanowells gives a greater signal to background ratio in measurements with a long time domain (such as cyclic voltammetry at scan rates below $5 \mathrm{mV} \mathrm{s}^{-1}$ ) than with a planar electrode of the same geometric area because concentration gradients at the head of the pore form hemispheres that do not overlap. Modification of the electrode with a dense array of pores does not give hemispherical diffusion. Regardless of diameter, the versatility of pores perpendicular to the electrode surface in sol-gel films can be expanded by processing that adds functional groups.

Processing by EASA produces a film with $0.7-2 \mathrm{~nm}$ pores in a tightly packed geometric array. Adding an electrontransfer mediator to the precursor sol that interacts with the surfactant templating agent greatly enhances the charge transfer property of these films by site-to-site electron selfexchange when the mediator is closely packed. Moreover, this approach can make the surface of the film an electron-transfer mediator. As a result, these films have an intrinsic characteristic of causing the electrode reaction to occur at the outer surface of the film. The small diameter of these templated pores facilitates the elimination of passivation of the system by adsorption of the product of the electrode reaction as well as resisting perturbation of the electrode by adsorption of matrix components. Removal of the surfactant after film formation can produce vertical pores that share the characteristics described above. The versatility of EASA is exhibited in recent studies that involve modification of the side chains of the precursor sol. For example, depending on the substitution the hydrophilic pore volume can be made hydrophobic, and a route to making the pore wall a densely packed electrontransfer mediator is available. When the goal is to prepare a catalytic surface for electroanalytical measurements, this processing method, especially with a mediator in the surfactant channel, will yield the same current as that at an electrode the same diameter as the base electrode and with the same catalysis (absent the sol-gel film) because the overlapping diffusion zone in the sample effectively makes the effective electrode area the same.

Sol-gel frameworks can be designed into three-electrode cells, which can operate as gas sensors. The electron-transfer 
process can involve partitioning the analyte into the electrolyte; however, protruding the working electrode into the gas phase results in electron transfer at the three-phase boundary among the electrolyte, electrode, and the gaseous sample. The response time with the latter design is sufficiently rapid to serve as a detector in gas chromatography. The electrolyte can be selected to give a humidity-independent response. A promising approach for future work is to apply the general concept to microarrays in gas-flow systems. The rapid response at the three-phase boundary along with the fact that the response of an amperometric measurement depends on the dimension of the diffusion zone at the electrode surface rather than the bulk dimension favors electrochemical measurement over many other transducers. Finally, the use of roomtemperature ionic liquids in combination with a silica framework is a promising approach for extending the use of sol-gel science in electroanalytical chemistry.

Funding information This work was supported in part by Project No. 2015/19/B/ST4/03758 (National Science Centre - Poland) to K.M.

Open Access This article is licensed under a Creative Commons Attribution 4.0 International License, which permits use, sharing, adaptation, distribution and reproduction in any medium or format, as long as you give appropriate credit to the original author(s) and the source, provide a link to the Creative Commons licence, and indicate if changes were made. The images or other third party material in this article are included in the article's Creative Commons licence, unless indicated otherwise in a credit line to the material. If material is not included in the article's Creative Commons licence and your intended use is not permitted by statutory regulation or exceeds the permitted use, you will need to obtain permission directly from the copyright holder. To view a copy of this licence, visit http://creativecommons.org/licenses/by/4.0/.

\section{References}

1. Alber KS, Cox JA (1997) Electrochemistry in solids prepared by sol-gel processes. Microchim Acta 127:131-147. https://doi.org/ 10.1007/BF01242718

2. Lev O, Wu Z, Bharathi S et al (1997) Sol-gel materials in electrochemistry. Chem Mater 9:2354-2375. https://doi.org/10.1021/ cm970367b

3. Wang J (1999) Sol-gel materials for electrochemical biosensors. Anal Chim Acta 399:21-27. https://doi.org/10.1016/S00032670(99)00572-3

4. Walcarius A (2001) Electrochemical applications of silica-based organic-inorganic hybrid materials. Chem Mater 13:3351-3372. https://doi.org/10.1021/cm0110167

5. Opallo M (2002) The electrochemical redox reactions in solvated silica sol-gel glass. Mater Sci-Pol 20:7-14

6. Walcarius A, Mandler D, Cox JA et al (2005) Exciting new directions in the intersection of functionalized sol-gel materials with electrochemistry. J Mater Chem 15:3663-3689. https://doi.org/10. 1039/B504839G

7. Collinson MM (2007) Electrochemistry: an important tool to study and create new sol-gel-derived materials. Acc Chem Res 40:777783. https://doi.org/10.1021/ar600029p
8. Cox JA (2011) Modification of electrodes with catalytic, sizeexclusion films. J Solid State Electrochem 15:1495-1507. https:// doi.org/10.1007/s10008-011-1366-Z

9. Membreno D, Smith L, Dunn B (2014) Silica sol-gel chemistry: creating materials and architectures for energy generation and storage. J Sol-Gel Sci Technol 70:203-215. https://doi.org/10.1007/ s10971-014-3299-3

10. Donato KZ, Matejka L, Mauler RS, Donato RK (2017) Recent applications of ionic liquids in the sol-gel process for polymersilica nanocomposites with ionic interfaces. Colloids Interfaces 1 : 5-30. https://doi.org/10.3390/colloids1010005

11. Morosanova EI (2018) Silica-titania sol-gel materials: synthesis and analytical applications. J Anal Chem 73:1043-1052. https:// doi.org/10.1134/S1061934818110072

12. Brinker CJ, Scherer GW (1990) Sol-gel science. In: Sol-Gel Science. Academic Press, San Diego

13. Walcarius A (2001) Electroanalysis with pure, chemically modified and sol-gel-derived silica-based materials. Electroanalysis 13:701718. https://doi.org/10.1002/1521-4109(200105)13:8/9<701::AIDELAN701>3.0.CO;2-6

14. Shapiro L, Marx S, Mandler D (2007) Preparation and characterization of ultra-thin sol-gel films. Thin Solid Films 515:4624-4628. https://doi.org/10.1016/j.tsf.2006.11.117

15. Zeng Y, Li C, Tang C et al (2006) The electrochemical properties of Co(TPP), tetraphenylborate modified glassy carbon electrode: application to dopamine and uric acid analysis. Electroanalysis 18: 440-448. https://doi.org/10.1002/elan.200503405

16. Olívio PHP, Correia LA, Paula JH et al (2018) Exploring electrochemical reactivity toward ametryn of hybrid silicate films with phosphomolybdic acid. Mater Sci Eng B 229:13-19. https://doi. org/10.1016/j.mseb.2017.12.014

17. Song W, Liu Y, Lu N et al (2000) Application of the sol-gel technique to polyoxometalates: towards a new chemically modified electrode. Electrochim Acta 45:1639-1644. https://doi.org/10. 1016/S0013-4686(99)00326-6

18. Wang Q, Lu G, Yang B (2004) Direct electrochemistry and electrocatalysis of hemoglobin immobilized on carbon paste electrode by silica sol-gel film. Biosens Bioelectron 19:1269-1275. https://doi.org/10.1016/j.bios.2003.11.012

19. Shacham R, Avnir D, Mandler D (1999) Electrodeposition of methylated sol-gel films on conducting surfaces. Adv Mater 11:384 388. https://doi.org/10.1002/(SICI)1521-4095(199903)11:5<384:: AID-ADMA384>3.0.CO;2-M

20. Shacham R, Avnir D, Mandler D (2004) Electrodeposition of dyedoped titania thin films. J Sol-Gel Sci Technol 31:329-334. https:// doi.org/10.1023/B:JSST.0000048012.14882.38

21. Shacham R, Mandler D, Avnir D (2004) Electrochemically induced sol-gel deposition of zirconia thin films. Chem Eur J 10:19361943. https://doi.org/10.1002/chem.200305469

22. Wandstrat MM, Spendel WU, Pacey GE, Cox JA (2007) Oxidation of a phospholipid at an electrode modified with an electrochemically formed sol-gel film doped with cyclodextrin. Electroanalysis 19: 139-143. https://doi.org/10.1002/elan.200603678

23. Ohira A, Ishizaki T, Sakata M et al (2000) Formation of the "nanotube' structure of $\beta$-cyclodextrin on $\mathrm{Au}(\mathrm{III})$ surfaces induced by potential controlled adsorption. Colloids Surf A Physicochem Eng Asp 169:27-33. https://doi.org/10.1016/S0927-7757(00)00413-1

24. Li J, Piehler LT, Qin D et al (2000) Visualization and characterization of poly(amidoamine) dendrimers by atomic force microscopy. Langmuir 16:5613-5616. https://doi.org/10.1021/la000035c

25. Tanev PT, Liang Y, Pinnavaia TJ (1997) Assembly of mesoporous lamellar silicas with hierarchical particle architectures. J Am Chem Soc 119:8616-8624. https://doi.org/10.1021/ja970228v

26. Walcarius A, Sibottier E, Etienne M, Ghanbaja J (2007) Electrochemically assisted self-assembly of mesoporous silica thin films. Nat Mater 6:602-608. https://doi.org/10.1038/nmat1951 
27. Despas C, Vodolazkaya NA, Ghanbaja J, Walcarius A (2015) Preparation of ordered and oriented mesoporous silica thin films bearing octyl or hexadecyl groups by electrochemically assisted self-assembly and evaluation of their transport properties. J Solid State Electrochem 19:2075-2085. https://doi.org/10.1007/s10008014-2726-2

28. Polarz S, Smarsly B, Bronstein L, Antonietti M (2001) From cyclodextrin assemblies to porous materials by silica templating. Angew Chem Int Ed 40:4417-4421. https://doi.org/10.1002/ 1521-3773(20011203)40:23<4417::AID-ANIE4417>3.0.CO;2-P

29. Berrettoni M, Giorgetti M, Cox JA et al (2012) Electrochemical synthesis of nano-cobalt hexacyanoferrate at a sol-gel-coated electrode templated with $\beta$-cyclodextrin. J Solid State Electrochem 16: 2861-2866. https://doi.org/10.1007/s10008-012-1714-7

30. Khramov AN, Munos J, Collinson MM (2001) Preparation and characterization of macroporous silicate films. Langmuir 17: 8112-8117. https://doi.org/10.1021/la010112j

31. Kanungo M, Deepa PN, Collinson MM (2004) Template-directed formation of hemispherical cavities of varying depth and diameter in a silicate matrix prepared by the sol-gel process. Chem Mater 16: 5535-5541. https://doi.org/10.1021/cm049270x

32. Mehdi BL, Rutkowska IA, Kulesza PJ, Cox JA (2013) Electrochemically assisted fabrication of size-exclusion films of organically modified silica and application to the voltammetry of phospholipids. J Solid State Electrochem 17:1581-1590. https:// doi.org/10.1007/s10008-013-2077-4

33. Ciabocco M, Berrettoni M, Zamponi S, Cox JA (2015) Immobilization of nanobeads on a surface to control the size, shape, and distribution of pores in electrochemically generated sol-gel films. J Solid State Electrochem 19:2087-2094. https:// doi.org/10.1007/s10008-014-2709-3

34. Hierlemann A, Campbell JK, Baker LA et al (1998) Structural distortion of dendrimers on gold surfaces: a tapping-mode AFM investigation. J Am Chem Soc 120:5323-5324. https://doi.org/10. 1021/ja974283f

35. Pericet-Camara R, Papastavrou G, Borkovec M (2004) Atomic force microscopy study of the adsorption and electrostatic selforganization of poly(amidoamine) dendrimers on mica. Langmuir 20:3264-3270. https://doi.org/10.1021/la035955k

36. Rutkowska IA, Sek JP, Mehdi BL et al (2014) Assembly of crosslinked oxo-cyanoruthenate and zirconium oxide bilayers: application in electrocatalytic films based on organically modified silica with templated pores. Electrochim Acta 122:197-203. https://doi.org/10.1016/j.electacta.2013.11.091

37. Ciabocco M, Berrettoni M, Zamponi S, Cox JA (2016) Deposition and characterization of a CoHCF nanorod array in a templated ormosil film on an electrode and application to electrocatalysis. $\mathrm{J}$ Solid State Electrochem 20:1323-1329. https://doi.org/10.1007/ s10008-016-3123-9

38. Cheng W, Dong S, Wang E (2002) Gold nanoparticles as fine tuners of electrochemical properties of the electrode/solution interface. Langmuir 18:9947-9952. https://doi.org/10.1021/la026022b

39. Zhang J, Kambayashi M, Oyama M (2004) A novel electrode surface fabricated by directly attaching gold nanospheres and nanorods onto indium tin oxide substrate with a seed mediated growth process. Electrochem Commun 6:683-688. https://doi.org/10.1016/j. elecom.2004.05.006

40. Ca DV, Sun L, Cox JA (2006) Optimization of the dispersion of gold and platinum nanoparticles on indium tin oxide for the electrocatalytic oxidation of cysteine and arsenite. Electrochim Acta 51: 2188-2194. https://doi.org/10.1016/j.electacta.2005.04.084

41. Shakila V, Pandian K (2007) Preparation of gold nanoislands on various functionalized polymer-modified glass and ITO for electrochemical characterization of monolayer assembly of alkanethiols. J Solid State Electrochem 11:296-302. https://doi.org/10.1007/ s10008-006-0107-1
42. Cox JA, Kulesza PJ (1984) Electrocatalytic oxidation and determination of arsenic(III) on a glassy carbon electrode modified with a thin film of mixed-valent ruthenium(III, II) cyanide. Anal Chem 56: 1021-1025. https://doi.org/10.1021/ac00270a034

43. Zhang B, Zhang Y, White HS (2004) The nanopore electrode. Anal Chem 76:6229-6238. https://doi.org/10.1021/ac049288r

44. Zhang B, Zhang Y, White HS (2006) Steady-state voltammetric response of the nanopore electrode. Anal Chem 78:477-483. https://doi.org/10.1021/ac051330a

45. Lanyon YH, De Marzi G, Watson YE et al (2007) Fabrication of nanopore array electrodes by focused ion beam milling. Anal Chem 79:3048-3055. https://doi.org/10.1021/ac061878x

46. Miller CJ, Majda M (1985) Microporous aluminum oxide films at electrodes. J Am Chem Soc 107:1419-1420. https://doi.org/10. 1021/ja00291a056

47. Brzózka A, Jeleń A, Brudzisz AM et al (2017) Electrocatalytic reduction of chloroform at nanostructured silver electrodes. Electrochim Acta 225:574-583. https://doi.org/10.1016/j. electacta.2016.12.111

48. Li X, Zhang T, Gao P et al (2018) Integrated solid-state nanopore electrochemistry array for sensitive, specific, and label-free biodetection. Langmuir 34:14787-14795. https://doi.org/10.1021/ acs.langmuir.8b02010

49. Li C, He L, Jiang S et al (2019) Ultrasensitive detection of microRNA using an array of Au nanowires deposited within the channels of a porous anodized alumina membrane. Electrochem Commun 102:19-24. https://doi.org/10.1016/j.elecom.2019.03. 008

50. Tavella F, Ampelli C, Lronardi SG, Neri G (2018) Photoelectrochemical sensing of dopamine by a novel porous $\mathrm{TiO}_{2}$ array-modified screen-printed Ti electrode. Sensors 18:3566-3577

51. Lalo H, Bon-Saint-Côme Y, Plano B et al (2012) Site selective generation of sol-gel deposits in layered bimetallic macroporous electrode architectures. Langmuir 28:2323-2326. https://doi.org/ 10.1021/la204679u

52. Tsionsky M, Gun G, Glezer V, Lev O (1994) Sol-gel-derived ceramic-carbon composite electrodes: introduction and scope of applications. Anal Chem 66:1747-1753. https://doi.org/10.1021/ ac00082a024

53. Gavalas VG, Law SA, Christopher Ball J et al (2004) Carbon nanotube aqueous sol-gel composites: enzyme-friendly platforms for the development of stable biosensors. Anal Biochem 329:247-252. https://doi.org/10.1016/j.ab.2004.02.025

54. Wang Z, Etienne M, Urbanova V et al (2013) Reagentless dsorbitol biosensor based on d-sorbitol dehydrogenase immobilized in a sol-gel carbon nanotubes-poly(methylene green) composite. Anal Bioanal Chem 405:3899-3906. https://doi.org/10.1007/ s00216-013-6820-6

55. Urbanová V, Etienne M, Walcarius A (2013) One step deposition of sol-gel carbon nanotubes biocomposite for reagentless electrochemical devices. Electroanalysis 25:85-93. https://doi.org/10. 1002/elan.201200407

56. Chen Q, Kenausis GL, Heller A (1998) Stability of oxidases immobilized in silica gels. J Am Chem Soc 120:4582-4585. https://doi.org/10.1021/ja971750k

57. Ragupathy D, Gopalan AI, Lee K-P (2010) Electrocatalytic oxidation and determination of ascorbic acid in the presence of dopamine at multiwalled carbon nanotube-silica network-gold nanoparticles based nanohybrid modified electrode. Sensors Actuators B Chem 143:696-703. https://doi.org/10.1016/j.snb.2009.10.026

58. Salimi A, Roushani M (2006) Electrocatalytic oxidation of sulfur containing amino acids at renewable ni-powder doped carbon ceramic electrode: application to amperometric detection L-cystine, L-cysteine and L-methionine. Electroanalysis 18:2129-2136. https://doi.org/10.1002/elan.200603639 
59. Ferrag C, Noroozifar M, Kerman K (2020) Thiol functionalized carbon ceramic electrode modified with multi-walled carbon nanotubes and gold nanoparticles for simultaneous determination of purine derivatives. Mater Sci Eng C 110:110568. https://doi.org/10. 1016/j.msec.2019.110568

60. Celebanska A, Tomaszewska D, Lesniewski A, Opallo M (2011) Film electrode prepared from oppositely charged silicate submicroparticles and carbon nanoparticles for selective dopamine sensing. Biosens Bioelectron 26:4417-4422. https://doi.org/10. 1016/j.bios.2011.04.054

61. Lesniewski A, Niedziolka-Jonsson J, Rizzi C et al (2010) Carbon ceramic nanoparticulate film electrode prepared from oppositely charged particles by layer-by-layer approach. Electrochem Commun 12:83-85. https://doi.org/10.1016/j.elecom.2009.10.041

62. Szot K, Lynch RP, Lesniewski A et al (2011) The effect of linker of electrodes prepared from sol-gel ionic liquid precursor and carbon nanoparticles on dioxygen electroreduction bioelectrocatalysis. Electrochim Acta 56:10306-10312. https://doi.org/10.1016/j. electacta.2011.03.139

63. Celebanska A, Opallo M (2016) Layer-by-layer gold-ceramic nanoparticulate electrodes for electrocatalysis. ChemElectroChem 3:1629-1634. https://doi.org/10.1002/celc.201600288

64. Cox JA, Wiaderek KM, Mehdi BL et al (2011) Influence of silanization on voltammetry at electrodes modified with silica films of controlled porosity formed by electrochemically initiated sol-gel processing. J Solid State Electrochem 15:2409-2417. https://doi. org/10.1007/s10008-011-1445-1

65. Evans MB, Dale AD, Little CJ (1980) The preparation and evaluation of superior bonded phases for reversed-phase, highperformance liquid chromatography. Chromatographia 13:5-10. https://doi.org/10.1007/BF02302709

66. Qiu B, Chen X, Chen H-L, Chen G-N (2007) Electrochemiluminescence determination of codeine or morphine with an organically modified silicate film immobilizing $\mathrm{Ru}(\mathrm{bpy})_{3}{ }^{2+}$. Luminescence 22:189-194. https://doi.org/10.1002/ bio. 947

67. Walcarius A (2018) Silica-based electrochemical sensors and biosensors: recent trends. Curr Opin Electrochem 10:88-97. https:// doi.org/10.1016/j.coelec.2018.03.017

68. Serrano MB, Despas C, Herzog G, Walcarius A (2015) Mesoporous silica thin films for molecular sieving and electrode surface protection against biofouling. Electrochem Commun 52: 34-36. https://doi.org/10.1016/j.elecom.2015.01.010

69. Vilà N, André E, Ciganda R et al (2016) Molecular sieving with vertically aligned mesoporous silica films and electronic wiring through isolating nanochannels. Chem Mater 28:2511-2514. https://doi.org/10.1021/acs.chemmater.6b00716

70. Chu C, Liu C, Jiang L et al (2019) On-line synergistic stacking in capillary zone electrophoresis featuring field-amplified sample stacking and micelle to cyclodextrin stacking in the determination of two alkaloids in complicated matrix samples. J Sep Sci 42:30093015. https://doi.org/10.1002/jssc.201900482

71. Liu C, Lambert JB, Fu L (2004) Simple surfactant-free route to mesoporous organic-inorganic hybrid silicas containing covalently bound cyclodextrins. J Organomet Chem 69:2213-2216. https:// doi.org/10.1021/jo0352979

72. Ranganathan $\mathrm{D}$, Zamponi S, Berrettoni $\mathrm{M}$ et al (2010) Oxidation and flow-injection amperometric determination of 5hydroxytryptophan at an electrode modified by electrochemically assisted deposition of a sol-gel film with templated nanoscale pores. Talanta 82:1149-1155. https://doi.org/10.1016/j.talanta. 2010.06.025

73. Wiaderek KM, Cox JA (2011) Preparation and electrocatalytic application of composites containing gold nanoparticles protected with rhodium-substituted polyoxometalates. Electrochim Acta 56: 3537-3542. https://doi.org/10.1016/j.electacta.2010.09.039
74. Cox JA, Rutkowska IA, Kulesza PJ (2020) Critical reviewelectrocatalytic sensors for arsenic oxo species. J Electrochem Soc 167:037565. https://doi.org/10.1149/1945-7111/ab697d

75. Ahoulou S, Vilà N, Pillet S et al (2020) Non-covalent immobilization of iron-triazole $\left(\mathrm{Fe}(\mathrm{Htrz})_{3}\right)$ molecular mediator in mesoporous silica films for the electrochemical detection of hydrogen peroxide. Electroanalysis 32:690-697. https://doi.org/10.1002/elan. 201900444

76. Maheshwari H, Vilà N, Herzog G, Walcarius A (2020) Selective detection of cysteine at a mesoporous silica film electrode functionalized with ferrocene in the presence of glutathione. ChemElectroChem 7:2095-2101. https://doi.org/10.1002/celc. 202000396

77. Makote R, Collinson MM (1998) Dopamine recognition in templated silicate films. Chem Commun:425-426. https://doi.org/10. 1039/A705536F

78. Makote R, Collinson MM (1998) Template recognition in inorganic-organic hybrid films prepared by the sol-gel process. Chem Mater 10:2440-2445. https://doi.org/10.1021/cm9801136

79. Chen J, Huang H, Zeng Y et al (2015) A novel composite of molecularly imprinted polymer-coated PdNPs for electrochemical sensing norepinephrine. Biosens Bioelectron 65:366-374. https:// doi.org/10.1016/j.bios.2014.10.011

80. Akhoundian M, Alizadeh T, Pan G (2020) Fabrication of the enzyme-less voltammetric bilirubin sensor based on sol-gel imprinted polymer. Electroanalysis 32:479-488. https://doi.org/ 10.1002/elan.201900410

81. Deiminiat B, Razavipanah I, Rounaghi GH, Arbab-Zavar MH (2017) A novel electrochemical imprinted sensor for acetylsalicylic acid based on polypyrrole, sol-gel and $\mathrm{SiO}_{2} @ \mathrm{Au}$ core-shell nanoparticles. Sensors Actuators B Chem 244:785-795. https://doi.org/ 10.1016/j.snb.2017.01.059

82. Miecznikowski K, Cox JA, Lewera A, Kulesza PJ (2000) Solid state voltammetric characterization of iron hexacyanoferrate encapsulated in silica. J Solid State Electrochem 4:199-204. https://doi. org $/ 10.1007 / \mathrm{s} 100080050195$

83. Holmstrom SD, Cox JA (1998) Solid-state voltammetric determination of gaseous hydrogen peroxide using nanostructured silica as the electrolyte. Electroanalysis 10:597-601. https://doi.org/10. 1002/(SICI)1521-4109(199807)10:9<597::AID-ELAN597>3.0. $\mathrm{CO} ; 2-\mathrm{B}$

84. Huang H, Dasgupta PK, Genfa Z, Wang J (1996) A pulse amperometric sensor for the measurement of atmospheric hydrogen peroxide. Anal Chem 68:2062-2066. https://doi.org/10.1021/ ac960143x

85. Tess ME, Cox JA (1998) Humidity-independent solid-state amperometric sensor for carbon monoxide based on an electrolyte prepared by sol-gel chemistry. Anal Chem 70:187-190. https://doi. org/10.1021/ac9708396

86. Yasuda A (1992) Mechanism of the sensitivity of the planar CO sensor and its dependency on humidity. J Electrochem Soc 139: 3224. https://doi.org/10.1149/1.2069057

87. Holmstrom SD, Sandlin ZD, Steinecker WH, Cox JA (2000) Mediated oxidation and determination of gaseous monomethyl hydrazine in a solid-state voltammetric cell employing a sol-gel electrolyte. Electroanalysis 12:262-266. https://doi.org/10.1002/(SICI) 1521-4109(20000301)12:4<262::AID-ELAN262>3.0.CO;2-F

88. Steinecker WH, Miecznikowski K, Kulesza PJ et al (2017) Amperometric detector for gas chromatography based on a silica sol-gel solid electrolyte. Talanta 174:1-6. https://doi.org/10.1016/j. talanta.2017.05.074

89. Huang X-J, Aldous L, O'Mahony AM et al (2010) Toward membrane-free amperometric gas sensors: a microelectrode array approach. Anal Chem 82:5238-5245. https://doi.org/10.1021/ ac1006359 
90. Xiong L, Goodrich P, Hardacre C, Compton RG (2013) Evaluation of a simple disposable microband electrode device for amperometric gas sensing. Sensors Actuators B Chem 188:978-987. https:// doi.org/10.1016/j.snb.2013.07.104

91. Dossi N, Toniolo R, Pizzariello A et al (2012) An electrochemical gas sensor based on paper supported room temperature ionic liquids. Lab Chip 12:153-158. https://doi.org/10.1039/C1LC20663J

92. Wang Z, Lin P, Baker GA et al (2011) Ionic liquids as electrolytes for the development of a robust amperometric oxygen sensor. Anal Chem 83:7066-7073. https://doi.org/10.1021/ac201235w

93. Dai S, Ju YH, Gao HJ et al (2000) Preparation of silica aerogel using ionic liquids as solvents. Chem Commun:243-244. https:// doi.org/10.1039/A907147D

94. Göbel R, Hesemann P, Weber J et al (2009) Surprisingly high, bulk liquid-like mobility of silica-confined ionic liquids. Phys Chem Chem Phys 11:3653-3662. https://doi.org/10.1039/B821833A

95. Noor SAM, Bayley PM, Forsyth M, MacFarlane DR (2013) Ionogels based on ionic liquids as potential highly conductive solid state electrolytes. Electrochim Acta 91:219-226. https://doi.org/10. 1016/j.electacta.2012.11.113
96. Le Bideau J, Ducros J-B, Soudan P, Guyomard D (2011) Solidstate electrode materials with ionic-liquid properties for energy storage: the lithium solid-state ionic-liquid concept. Adv Funct Mater 21:4073-4078. https://doi.org/10.1002/adfm.201100774

97. Chang W-Q, Apodaca DC, Peng W-C, Chen-Yang Y-W (2018) Protic ionic liquid-containing silica-based ionogels for nonhumidified PEMFC applications. Ionics 24:469-481. https:// doi.org/10.1007/s11581-017-2212-9

98. Ribet F, De Pietro L, Roxhed N, Stemme G (2018) Gas diffusion and evaporation control using EWOD actuation of ionic liquid microdroplets for gas sensing applications. Sensors Actuators B Chem 267:647-654. https://doi.org/10.1016/j.snb.2018.04.076

99. Liu X, Chen X, Xu Y et al (2019) Effects of water on ionic liquid electrochemical microsensor for oxygen sensing. Sensors Actuators B Chem 285:350-357. https://doi.org/10.1016/j.snb.2019.01.026

Publisher's note Springer Nature remains neutral with regard to jurisdictional claims in published maps and institutional affiliations. 